\title{
The Portrayal of Tuberculosis in Cinema
}

\author{
Sofia Gourgoulianni, PhD \\ Department of Economics \\ University of Thessaly \\ Greece
}

\begin{abstract}
Undoubtedly, art is intrigued by human pain, its' management by man and its' consequences in various aspects of his life. Moreover, creation and inspiration often result from difficult periods of ones' life associated with grief and suffering. Infectious diseases which have taken the form of plagues, like tuberculosis, are also linked to these negative feelings. Therefore, they have also been a significant source of inspiration for various art forms. In this paper, we will analyze the relation between cinema and tuberculosis, examining the ways in which it has been treated in relation to human behavior in a number of different cases.
\end{abstract}

Throughout history, mankind has suffered from plenty of infectious diseases which have shaped or even altered history and social evolution. A large number of them have been significant enough to affect how and where we live, our economies, our cultures and daily habits. Moreover, many of the effects they have had on people's lives and their general welfare continue long after the diseases have been eliminated. (Whittaker, 2017).

Illness, as a notion, in everyday life, is mostly linked to pain and constant suffering. Upon the hearing of the word disease, one is inclined to recall memories of grief. The disease in real life coincides with pessimism and seems to exclude the pleasures of life of the people affected. One of these plagues which has infected man and has been particularly connected to suffering is tuberculosis.

Art has always been interested in events which have shaped social evolution. Moreover, it often depicts human pain and the various consequences it has triggered in the history of mankind. As tuberculosis has been an important plague for man, it has also been a subject for various arts, like literature, in the novels of Fyodor Dostoyevsky (Crime and Punishment 1866, Demons 1872, The Idiot 1869) and Thomas Mann (The Magic Mountain 1924) and fine art, like in Edvard Munch's work in his paintings Dead Mother and The Sick Child (Grogaard, 2013). In this paper, we will analyze the way in which tuberculosis has been treated in cinema.

As far as tuberculosis is regarded, it is, undoubtedly, an ancient scourge. It has plagued humankind throughout known history and human prehistory. Modern strains of tuberculosis appear to have originated from a common ancestor about 20,000-15,000 years ago. In Egypt, tuberculosis can be documented for more than 5000 years ago. Typical skeletal abnormalities of tuberculosis, have been found in Egyptian mummies and are clearly depicted in early Egyptian art. In addition, there are written texts describing tuberculosis in India as early as 3300 years ago and in China 2300 years ago. Tuberculosis was well known in classical Greece, where it was called phthisis. Hippocrates clearly recognized tuberculosis and understood its clinical presentation. "Phthisis makes its attacks chiefly between the age of eighteen and thirty-five," he wrote in his aphorisms, clearly recognizing the predilection of young adults for active tuberculosis.

As Europe entered the middle ages, the written record of tuberculosis becomes sparse. This does not mean that the disease was not present. As the renaissance swept northward from Italy into Northern Europe, new knowledge emerged, including new knowledge of the disease. In the $19^{\text {th }}$ century tuberculosis had surged across Europe in an epidemic tsunami. In the late $19^{\text {th }}$ century the phenomenon and the death rates declined, however ill patients sought comfort and relief and retreated frequently to sanatoria (Daniel 2006). In the sanatoria, the patients led a lonely life secluded not only from their family and beloved ones but also from the whole world and the changes that occurred outside the walls of the sanatorium. The loneliness that was undoubtedly linked to life in the sanatoria, frequently caused the development of bonds between patients who not only shared the same state of health, but also the notion of the world outside the walls of the sanatorium. It is, therefore, clear, that tuberculosis has emerged as an integral part of human history. Consequently, we can conclude that the history of sanatoria represents part of the lives of an immense number of people during the $20^{\text {th }}$ century and can be considered as a truly important part of the social evolution of the previous century. As far as cinema is concerned, even though it is an invention of the $20^{\text {th }}$ century, it has always treated historical matters and human pain as a matter that triggers reactions and various consequences. Consequently, tuberculosis has always intrigued film directors and scriptwriters and has participated in several of their films either as central or as peripheral subject. 
Tuberculosis has been treated as a movie subject, firstly, as a state that causes suffering and also as a state that triggers loneliness and isolation from beloved ones. However, cinema also explores aspects of the disease that can lead to optimistic moments. Because of this dual nature of the disease, and its treatment in cinema, the study of films that concerned tuberculosis, presents important and remarkable aspects.

In this paper, we will present briefly the most important films linked to the subject of tuberculosis. Subsequently, we will analyze, in the form of case studies, five films concerning the subject in order to study the way in which they treat the disease. The basic matter that will be examined is the impact of tuberculosis on human reactions and interpersonal relations.

\section{The Butterfly's Dream (2013)}

The first movie we will analyze thoroughly is the 2013 movie "The Butterfly's Dream". The film is a Turkish production, directed by Yilmaz Erdogan starring Kivanc Tatlitug and Mert Firat. The film was particularly famous in Turkey, where its admissions reached the number of 2.159.540. Moreover, it won multiple awards by the Turkish Film Critics Association in 2013 (Best Actor, Best Supporting Actress, Best Soundtrack, Best Art Direction, and Best Cinematography). It was also screened in 6 countries in Europe (Austria, Switzerland, Germany, United Kingdom, Netherlands, Norway) with the total amount of admissions being 89.188. (Lumiere Database).

The movie was chosen as one of the most important movies dealing with tuberculosis because the disease is one of its basic subjects. Tuberculosis is used by the scenario as a protagonist of the film and not only as the font of it. Both the male protagonists of the movie are ill with tuberculosis from the beginning till the end of the movie and the illness is the basic motive for all their actions. Used as a basic subject of the movie, this analysis will serve the purpose of explaining the way tuberculosis affected the reactions and lives of the movie's characters.

As far as the movie plot is concerned, the film is situated in a small Turkish town in 1941. During the World War 2, due to Obligation Law, all men inhabiting the Turkish Town are obliged to work in the mines. During this period, two poets in their early twenties are infected by tuberculosis. However, they continue desiring to live and create. Despite difficult political circumstances and their deteriorating health, they continue writing constantly and their ultimate dream is to publish their poems in a particular literary magazine and gain their life as famous poets.

At that time, they are also "infected" by the love for the same woman. In order to decide who will conquer her, they set a bet. They will both write a poem, they will present their poems to her and whoever's poem she prefers will win the bet and the girl. At the beginning, they both befriend the girl and for a short period of time they become a band of three. However, shortly afterwards, one of the two poets, Rustu, has to be hospitalized in a sanatorium because of his tuberculosis. The other poet, Muzaffer, quickly falls for the girl, Suzan, and they commence a relationship. However, their romance ends abruptly when her parents learn that not only Muzaffer is a poet but he also suffers from tuberculosis. Her parents are afraid that this romance does not have any future and, moreover, they are aware of the danger that their daughter may be also infected. In order to protect her from the disease and from a relationship which seems doomed, they prohibit her to continue seeing Muzaffer.

Muzaffer, after a short period of time, is also hospitalized for tuberculosis in the same sanatorium as Rustu. Upon his arrival their happiness to have found each other after a long time prevails. During his hospitalization Rustu has fallen in love with another patient, a beautiful young woman, named Farah. Their relationship began in the sanatorium but after some time they are both released and they decide to marry. Their future seems bright and their marriage is portrayed as a particularly joyful event which includes a lot of singing, dancing and of course laughs and smiles.

In the meantime, Muzaffer is also released from the sanatorium and tries to give a second chance to his romance with Suzan. Suzan welcomes him back and they continue their affair. However, Rustu's wife, Farah, falls seriously ill again. After a very short period Farah dies and Rustu suffers from grief. Muzaffer decides to stand by his friend at this extremely hard time. They close themselves in a room where they seek relief by writing constantly. Moreover, when Suzan comes to visit them, Muzaffer does not open to her and he seems to have quit their romance. Rustu also falls ill and dies. After the funeral of Rustu, Muzaffer is left alone at the graveyard and Suzan arrives. They hug each other and Suzan goes away. In the ending scene, we see Muzaffer standing alone in the graveyard.

As we have already noted, tuberculosis is the protagonist in this film as both the protagonists are infected by it and it is the basic incentive for their actions throughout the movie. As far as the beginning of the movie is concerned, it commences with the poets' knowledge of the disease they are affected, that is the two main actors of the film, knew from the very beginning, they had been already ill with tuberculosis. In the first minutes of the movie we observe the poets in their everyday life. Firstly, they are discussing about their poems, Muzaffer is optimistic that their poems will be accepted by the famous literature magazine, whereas Rustu is pessimistic. 
Afterwards, they set eyes upon a girl, Susan, and in the next days we see them discussing with their mentor, a famous poet and teacher, having dinner in the countryside, trying to sell their poems and paying a visit to Suzan's college. During their visit, Rustu starts spitting blood and has to be hospitalized. Consequently, we should note that although the poets have knowledge of their illness, they continue being creative, falling in love and continuing their life normally. As far as the aspect of falling in love is concerned, we should point out that the symptoms of tuberculosis are not yet severe and the disease in this phase can be identified as empowering their will to conquer Suzan. As the danger because of the illness is not yet severe, it is important to note that we see two different kinds of characters, the pessimist and the optimist. This different regard upon the illness will continue throughout the movie concerning their beliefs and the way they are facing tuberculosis.

During his hospitalization, Muzaffer visits Rustu and they discuss about poetry and the girl. Their discussion ends with Rustu expressing the opinion that love is an excuse for poetry and that they should continue writing poems, because they do not write poems only for Suzan, but for love. During his hospitalization, Muzaffer continues writing and in a scene, he is shown writing even in total dark. Despite his motivation to write poems, Rustu seems ill. Therefore, it is obvious that during his short hospitalization, Rustu tries to hold on to his ordinary life, which consisted of poetry and romance. As far as the treatment of the illness by both the protagonists is concerned, Muzaffer is also ill, but at that phase he has not manifested severe symptoms of tuberculosis and tries to stand by his friend. It is important to point out that once more illness is not an obstacle, but on the contrary it seems to be a motive for artistic creation and for consolidating human relations, as Rustu seems even more engaged to writing and Muzaffer spends time with him.

After a short period of time, Rustu is released and is seen on a steep rock with a view of the sea still writing. Muzaffer with Suzan arrive and they start discussing about her participating as an actress at a new play they are writing. Rustu, is not completely cured, however, he longs for life and he longs to continue writing and creating. It is also obvious that he longs for romance as he is also impressed by Suzan. At this phase, we see that Muzzafer is basically engaged to his romance with Suzan whereas Rustu seems to be heavily concerned with writing. We could identify his hospitalization as an incentive to continue writing and as a way of understanding that writing is his passion and destiny. It also seems that he may believe that his has not so much time left and that he should continue writing constantly.

As the film continues, we see the poets writing the play where Suzan is going to play a role and trying to direct it in order to be shown at the college. The illness here is not present. However, it always exists, menacing the health of the protagonists. Their rush and passion to complete the play and present it to an audience is attributed to the "phantom" of the disease which can manifest its symptoms at any time.

During a rehearsal for the play, Suzan's parents learn that the poets have tuberculosis and they arrive in order to warn them to stay away from her. Suzan leaves with her parents and some time afterwards, they see each other for the last time. Suzan asks if Muzzafer will be cured. He doesn't have an answer and she says goodbye. At this phase, even though the illness has not manifested its symptoms, it is closely connected to the loss of love and to separation. We should also point out that tuberculosis and its infectious character is portrayed as a source of impeding fear even at a time when its symptoms are not obvious yet.

Meanwhile, Rustu falls ill and has to be transferred to a sanatorium. In the scene where he says goodbye to Muzzafer, he urges him to continue his writing. At this time, Muzzafers' illness acts as a way of realizing that both their true "fates" are to become writers and they have to use their talent and passion even though their health is menaced. We should also point out that at the scene of Rustus' departure, even though we see him coughing, the portrayal of the illness is not particularly tragic as it is accompanied by smiles and seems to have a temporary character.

When Muzzafer is left alone, he searches for Suzan, he finds her and they decide that in order to continue their affair, she should be dressed as a man and they should go together to work at the mines. They put their plan into practice, however they are arrested and moreover, Muzzafer falls ill and has to be transferred to the sanatorium. At the beginning of these scenes, we can see that as far as love is concerned, it seems that it conquers the feelings of illness and drives to actions that ignore the disease and point to a common future. However, when Muzzafer falls ill, tuberculosis is again a source of separation and loss.

Muzzafer is finally transferred to the same sanatorium as Rustu. At this time, the disease seems to unite the two friends and is treated by the scenario as a means of solidarity between the friends, who are both happy to see each other. During their hospitalization, the illness is present, however they seem to indulge in simple pleasures of life and enforce their friendship. In addition, Rustu falls in love with Mediha, a fellow patient and asks her to marry him. Even though they are not completely cured, all three of them run away from the sanatorium. Muzzafer and Mediha have already decided to marry. Their love, at this time, prevails over tuberculosis and their marriage is presented as a particularly joyful event. 
After the marriage, Muzzafer meets again Suzan and they seem to be able, at last, to build their common future. Even though he is not cured, love once more seems to conquer illness. However, suddenly Mediha falls ill again and shortly afterwards dies. It is obvious that now tuberculosis is a source of grief and huge suffering. Moreover, love cannot prevail upon its disastrous consequences.

After the death of Mediha, Muzzafer decides to stand by Rustu and set aside his romance with Suzan. They stay in a room for days, engaged in writing. The illness is not only a source of grief but also a huge motivation for artistic creation. Rustu also dies and at his funeral we see Muzzafer left alone in front of his friend's grave. Suzan arrives to pay her condolences. She also hugs Muzzafer, they say goodbye and she leaves. The last impression of the movie is that tuberculosis is a source of grief.

However, after having analyzed the basic scenes concerning the illness, we should note that despite of the fact that the whole story is tragic and our last impression is that of sorrow and pain, upon reviewing the scenes of the movie, we observe that tuberculosis is not always treated as a subject of grief. From the first scenes, both the poets are full of energy and seek to write and enjoy the pleasures of life. They are aware of their illness and in spite of it they try very hard to express themselves through poetry. The illness works as an incentive for them to create and to live a life full of passion. As the movie continues, the illness is still there, however the two poets decide to continue poetry and claim the object of their love. Both of them decide, despite their illness, to try and build a future with the girls they love. They, also, continue writing even more intensively during the period that tuberculosis is at its peak. We should also add that throughout the movie, tuberculosis is a factor that makes the two poets' friendship stronger and is an incentive for the solidarity between them to become more intense. Consequently, even though the finale may seem tragic, the basic role of the disease is that it urges the protagonists to live their lives in full. The disease motivates the poets to seize the healthy days and indulge in the pleasures of life. Ultimately, the basic fact which is portrayed as an effect of the illness is the carpe diem effect, an incentive to love and create.

\section{Heavenly Creatures (1994)}

Heavenly Creatures is a 1994 film, a co-production of New Zealand and Germany, directed by Peter Jackson and starring Kate Winslet and Melanie Lynskey. It won the Silver Lion at the Venice Film Festival (1994) and was nominated for an Oscar in the category Best Screenplay Written Directly for the Screen. As far as admissions are concerned it reached 128.488 admissions in Europe where it was screened in 10 countries. In the USA the total gross amount was 3.049.135 dollars.

This film was chosen firstly as a film of artistic quality. Moreover, even though tuberculosis is not the basic subject of the film, it introduces an important aspect of illness, the effect of the disease during adolescence. Both our protagonists are adolescent girls dealing with two different illnesses, osteomyelitis for Pauline and tuberculosis for Juliet. In this film, the illness is used mostly as a font and not as a basic part of the plot. However, even though the protagonists seem healthy, disease has left its traces and as we will observe it acts as a motivation for the girls' actions.

As far as the plot is concerned, in New Zealand in 1952, Pauline an introvert young girl meets Juliet at school and quickly they create a very strong friendship. They come from a totally different family background, however they both share illness experiences and consequently can't participate in sport activities. Moreover, they share the same taste in music and films. After a short while they create a world of their own to play and create fantastic stories. When Juliet falls ill with tuberculosis Pauline tries to fill in her sentimental needs and lets a boy into her bed. However, when Juliet is healthy enough to return, they resume their friendship. But, quickly, both their parents are led to believe that this friendship is toxic and is becoming an obsession. In the end of the movie, the girls kill Juliet's mother Honora, in order to be free to continue their friendship.

The first trace of tuberculosis is seen at the beginning of the movie, when the girls meet each other. The two girls cannot engage in gymnastics because of their diseases. Pauline suffered from osteomyelitis and Juliet from tuberculosis. Juliet refers to tuberculosis as a lung disease and she says that she has scars in her lungs. Moreover, Juliet seems to feel disappointed because of her illness, whereas Pauline states that "all the best people have bone and lung diseases". We observe that the perspective towards illness defers totally between the two girls. At this point, tuberculosis is the basic factor that commences the relationship between the two girls. Tuberculosis along with osteomyelitis create a sense of common suffering. The girls seem to have passed similar difficulties, a fact that boosts their friendship and generates a sense of solidarity between them. In the next twenty minutes we see the girls building their friendship and creating an intense bond between them. They begin creating a world of their own called Borovina where their imaginary stories unfold. Finally, we should point out that the solid bond created between them, due to their common understanding of the world and their diseases, triggers their ultimate tragic action, murder, in order to ensure that they will continue their friendship without the obstacle of parental obligations. 


\section{The Immigrant (2013)}

The Immigrant is a 2013 film directed by James Gray which was nominated for the Palme d' Or at the Cannes Film Festival. Moreover, it was also nominated for and awarded in various film festivals around the world. We should also note that the film is a United States of America production and stars Marion Cotillard, Joaquin Phoenix and Jeremy Renner. As far as admissions are concerned, the film's worldwide gross was 7.585.011 dollars and the film was screened in 16 countries in Europe.

We include the film in this analysis as it is a film of the acclaimed director James Gray, which also received decent reviews and multiple awards. Moreover, it treats the illness in a special way, portraying the extent to which a person's actions can reach in order to save a beloved person from his illness. In the film plot, the sister of the basic protagonist is ill and all of her actions are driven by her need to save her sister.

In James Grays' film, two immigrant sisters, Ewa and Magda, from Poland arrive in New York City in 1921, escaping their home in Post- Great War Poland in order to lead a new and better life. Even though, both of them feel really optimistic about the opportunities awaiting for them in the USA, upon their arrival, one of the two sisters is diagnosed with tuberculosis, is quarantined and has to be left behind in Ellis Island.

The other sister has to leave to seek a new life, willing to sacrifice almost everything in order to earn money and be eventually reunited with her sister. It quickly proves to be extremely hard to survive in the streets of Manhattan for Ewa where she is almost deported, until she encounters Bruno a charming man who bribes the officers in order to let her go and avoid deportation. He also offers to take over and help her. However, Bruno, who in the first place seems to introduce her to the cosmopolitan lifestyle, finally forces her into prostitution. Moreover, he blackmails her to continue her activity as a prostitute promising that he can secure Magdas' release. However Bruno seems to fall for Ewa. The situation becomes complicated when Ewa meets Brunos' cousin, Emil, a magician, and falls in love with him. Ewa, by falling in love seems to regard Emil as her only chance to escape prostitution and Brunos's world. One day Emil visits Ewa in Brunos' house and promises Ewa that he will find the money in order to release her sister. However, when Bruno returns to the house he hides. In his attempt to kill Bruno, his gun backfires and he is killed. When Ewa is considered as a suspect for killing Emil, Bruno hides her from the police. However, when Bruno is beaten by the police, it is proven that Bruno has always had the money to pay for Magdas' release and was keeping it in order to hold Ewa near him. At this stage, Ewa persuades her aunt to give her the money for Magdas' release and Bruno pays his contact in the relevant authorities in order to release Magda. Bruno, who is now repentant, books tickets for the reunited sister who departs for New Jersey.

Here tuberculosis is a dark force which drives to actions that lead to unhappy choices and miserable lives. It is also seen as a fact which cannot be linked to an optimistic future, but only triggers drama and loss. Moreover, tuberculosis, is linked to complete isolation and separation, as Magda is quarantined and left back alone. Even if the disease leads to actions in order to succeed in finally recovering, the actions are often hasty and their consequences tragic. Finally, tuberculosis in the film is the constant expectation of a happy end, which however seems to be always left on hold.

\section{Drunken Angel (1948)}

Drunken Angel is a 1948 Akira Kurosawa film. It is not among the best known films of the acclaimed director, however it remains a film of high artistic quality. The film stars Takashi Shimura and Toshirô Mifune, both known at a worldwide level because of their participation in Kurosawa's films. The film was awarded at two film festivals of the time, the "Kinema Junpo Awards" and the "Manichi Film Concours". As far as admissions are concerned, it has not been possible to collect relevant data because of the 70 years that have passed since the projection of the film.

In the film, an alcoholic doctor Sanada (Takashi Shimura) treats a young man for a wound in his hand, but soon he realizes that his patient, Matsunaga is ill of tuberculosis. He, also, realizes that Matsunaga is a local gangster. During the treatment, the doctor forms a strong but uneasy, at times, friendship with Matsunaga. They seem to communicate well, however, they also quarrel frequently. The whole situation changes when the gangster's former boss, Okada, is released from prison. Matsunaga engages quickly in drinking and smoking with Okada and his health deteriorates. Even though the relation between Matsunaga and Okada seems solid, Matsunaga finds out that Okada is ready to betray him and sacrifice him against a rival gang. Matsunaga decides to confront him and he is killed in a knife fight. A local woman decides to bury his ashes in her farm, while Sanada learns than one of his patients is cured of tuberculosis.

This film does not concentrate on the sober and dark side of the illness. Tuberculosis is used in a way that triggers human relations. The doctor, Sanada, is lonely and the patient, Matsunaga, is worried. Tuberculosis gets between loneliness and fear and the two men form a solid friendship. Moreover, the disease is treated as a motive to engage in heroic actions and actions that will ensure the right to live. Consequently, Matsunaga decides to confront his former boss in order to fight for his life. 
Finally, tuberculosis is regarded as a situation which can inspire efforts to save peoples' lives. In the film, the doctor is seen as an instrument of optimism and self-sacrifice and the disease as a temporary situation which can also be associated to optimistic moments.

Consequently, as we have completed our analysis, we should conclude with the fact that the time during which tuberculosis was incurable was undoubtedly, a dark period in human history; however cinema has treated illness and more specifically tuberculosis, in various ways. The effort of screenwriters and directors does not concentrate on depicting, only, the pain and suffering. The difficulties caused by the disease are always present during every film, but, other situations are also portrayed. One of the most important aspects of tuberculosis is the influence it has on human relations. Patients may share loneliness and fear but these feelings can help create strong bonds either between patients or between the doctor and patients. These bonds concern both friendship and love relationships which also seem to flourish quickly because of the difficult health situation. Ultimately, as far as human relationships are concerned, they are treated as a source of trying to share pain and gain moments of happiness. We should also point out that tuberculosis drives film characters to, often hasty, actions. Acting impulsively, they try to either save their beloved ones or gain their own lives. Finally, an important aspect is this of the depiction of the doctor as a savior, who can even sacrifice himself in order to save his patients' lives.

\section{References}

Dostoyevsky F. (1866), Crime and Punishment, Bantam Classics, 1996.

Dostoyevsky F. (1872). Demons, Penguin Random House, 1995.

Dostoyevsky F. (1869). The Idiot, Penguin Random House, 2010.

Grogaard S. (2013). Munch 150 years. The lure of memory in The sick child, The Scandinavian Psychoanalytic Review, Volume 36, Issue 2.

Mann T. (1924). The Magic Mountain, Penguin Random House, 2015.

Whitaker M. (2017), How infectious diseases have shaped our culture, habits and language, The Conversation, (https://theconversation.com/how-infectious-diseases-have-shaped-our-culture-habits-and-language-75061). 